\title{
Involuntary status and mental capacity for treatment decisions under Sections 4, 3, and 57 of Ireland's Mental Health Act, 2001: analysis and recommendations for reform
}

\author{
Katherine Reidy ${ }^{1}$ and Brendan D. Kelly ${ }^{2 *}$ (D) \\ ${ }^{1}$ Registrar in Psychiatry, Department of Psychiatry, Trinity College Dublin, Trinity Centre for Health Sciences, Tallaght University Hospital, Dublin 24, D24 \\ NROA, Ireland \\ ${ }^{2}$ Professor of Psychiatry and Consultant Psychiatrist, Department of Psychiatry, Trinity College Dublin, Trinity Centre for Health Sciences, Tallaght University \\ Hospital, Dublin 24, D24 NROA, Ireland
}

\begin{abstract}
Although significant progress has been made in Irish mental health law in recent decades, the Mental Health Act, 2001 still falls short of properly protecting human rights. A consideration of human rights developments, both domestically and internationally, highlights the urgent need for reform. In this paper we consider Sections 4 ('Best interests'), 3 ('Mental disorder') and 57 ('Treatment not requiring consent') of the 2001 Act and related recommendations in the 2015 Report of the Expert Group on the Review of the Mental Health Act, 2001, and suggest specific areas for reform. Just as medicine evolves over time, so too does our understanding of human rights and law. While embracing a human rights-based approach to the extent suggested here might be seen as aspirational, it is important to balance achievable goals with higher ideals if progress is to be made and rights are to be respected.
\end{abstract}

Received 04 October 2020; Revised 13 December 2020; Accepted 23 December 2020

Keyword Mental health, treatment, mental capacity, legislation, human rights.

\section{Introduction}

People with mental illness are amongst the most vulnerable members of society (Kelly, 2005). While significant strides have been made in mental health law over recent decades, there is still much to be done. Recognition of human rights has evolved considerably in recent years, but Irish mental health law needs to continue to develop in order to keep pace with broader developments. Regrettably, the Mental Health Act, 2001 falls short of properly safeguarding the rights of people with mental illness and requires careful reconsideration in several areas. This paper focuses on Sections 4, 3, and 57 of the 2001 Act and related recommendations in the 2015 Report of the Expert Group on the Review of the Mental Health Act, 2001 (Expert Group on the Review of the Mental Health Act, 2001, 2015).

\section{Section 4: 'Best interests' and autonomy}

Section 4(1) of the Mental Health Act, 2001 states that in making a decision under this Act concerning the care or treatment of a person [...] the best interests of the person shall be the principal consideration with due regard being given to the interests of other persons who may be at risk of

${ }^{*}$ Address for correspondence: Professor Brendan Kelly, Department of Psychiatry, Trinity College Dublin, Trinity Centre for Health Sciences, Tallaght University Hospital, Dublin 24, D24 NR0A Ireland. (Email: brendan.kelly@tcd.ie) serious harm if the decision is not made'. With little guidance offered as to what is meant by 'best interests', the term remains open to many interpretations. While healthcare professionals might, at times, lament decisions made by patients, the requirement to respect a person's autonomy means respecting that person's right to make their own decisions, insofar as they are capable of making such decisions.

A human rights-based approach rooted in the principle of autonomy offers many advantages. In 2015, the Expert Group recommended that 'insofar as practicable, a rights-based approach should be adopted throughout any revised mental health legislation' (p.15). In Section 4(3) of the 2001 Act, reference is made to the right of the person to dignity, bodily integrity, privacy and autonomy', but the legislation does not accord these concepts the priority they merit (Beyleveld \& Brownsword, 2001). Increased emphasis on dignity and autonomy would not only reflect the ever-evolving body of case law in this area, but also limit the ambiguity, conflict and potential misuse associated with the concept of 'best interests' (Kelly, 2014).

Placing greater emphasis on dignity and autonomy would also be in keeping with increased recognition, both domestically and internationally, of the importance of fundamental rights, most notably in the UN Convention on the Rights of Persons With Disabilities (CRPD) (UN, 2006). In addition, Article 8 of the European Convention on Human Rights states that 
'everyone has the right to respect for [their] private and family life' (Council of Europe, 1950). The European Court of Human Rights (ECtHR) considered this article in the case of Pretty $v$ the United Kingdom, which related to assisted suicide, and emphasised 'the notion of personal autonomy (as) an important principle underlying the interpretation of its guarantees'. ${ }^{1}$

In this context, it is interesting to note the more recent shift in the language pertaining to autonomy; while the ECtHR had referred often to the concept of autonomy in the past, it had not described an explicit right (Koffeman, 2010). As has been pointed out, however, Judge Tulkens' dissenting opinion in the 2005 case of Leyla Şahin v. Turkey highlighted a 'real right to personal autonomy on the basis of Article 8 , ${ }^{2}$ which has since been illustrated by European case law over recent years (Koffeman, 2010). The importance of autonomy is also highlighted by Article 3 of the CRPD which sets out its general principles as including 'respect for inherent dignity, individual autonomy including the freedom to make one's own choices, and independence of persons'.

While there appears to be much support for a human rights-based approach in mental health legislation, there are also arguments in favour of retaining 'best interests' (Law Committee of the College of Psychiatrists of Ireland, 2016). In an appendix to the response of the College of Psychiatrists of Ireland's Law Committee to the 2015 review of the 2001 Act, the College's Faculty of Forensic Psychiatry stressed the fundamentality of 'best interests' to medical decision-making and the doctor-patient relationship. The faculty pointed to the ECtHR case of Winterwerp $v$ the Netherlands, which considered the detention of persons 'of unsound mind' and argued that the 'requirement for medical expertise in making a decision to detain an individual with a mental disorder' necessitates 'best interests (as) a guiding principle in making decisions for involuntary admissions under mental health legislation' (p.27). ${ }^{3}$

Many of those in favour of retaining 'best interests' acknowledge that, as it stands, the concept is open to misuse and that further definition is required in relation to how the idea ought to be interpreted with respect to human rights. Indeed, while there might be some difference of opinion in relation to the retention of 'best interests', it is clear that the current phrasing and interpretations do not adequately protect patients.

\footnotetext{
${ }^{1}$ Pretty v. United Kingdom 2346/02 [2002] ECHR 423. (https:/ / hudoc.echr.coe.int/fre\#\{\%22itemid\%22:[\%22001-60448\%22]\}) Accessed 28 September 2020.

${ }^{2}$ Leyla Şahin v. Turkey 44774/98 [2005] ECHR 819. (https:// hudoc.echr.coe.int/tur\#\{\%22itemid\%22:[\%22001-70956\%22]\}) Accessed 28 September 2020.

${ }^{3}$ Winterwerp v Netherlands 6301/73 [1979] ECHR 4. (https:// www.bailii.org/eu/cases/ECHR/1979/4.html) Accessed 28 September 2020.
}

If 'best interests' is retained in a revised 2001 Act, it would be wise to consider the approach of the Mental Capacity Act (Northern Ireland), 2016 (which has been commenced in part at time of writing). The Northern Irish legislation retains 'best interests' (Section 2) for any person over the age of 16 years who lacks the capacity to make specific decisions (Section 1), but provides guidelines for the interpretation of 'best interests' (Section 7). Any person determining what would be in the best interests of another person (' $\mathrm{P}^{\prime}$ ) 'must [among other requirements] have special regard to (so far as they are reasonably ascertainable) (a) P's past and present wishes and feelings (and, in particular, any relevant written statement made by P when P had capacity); (b) the beliefs and values that would be likely to influence $P^{\prime}$ s decision if $P$ had capacity; and (c) the other factors that $\mathrm{P}$ would be likely to consider if able to do so' (Section 7(6)).

In addition, they must '(a) so far as it is practicable and appropriate to do so, consult the relevant people about what would be in $\mathrm{P}^{\prime} \mathrm{s}$ best interests and in particular about the matters mentioned in subsection (6); and (b) take into account the views of those people (so far as ascertained from that consultation or otherwise) about what would be in P's best interests and in particular about those matters' (Section 7(7)). If 'best interests' is retained in Ireland's 2001 Act, similar interpretative guidelines would be useful.

\section{Section 3: 'Mental disorder' and criteria for involuntary admission}

Section 3(1) of the Mental Health Act, 2001 provides for the involuntary admission (but not involuntary treatment) of a person with 'mental disorder', where 'mental disorder' means 'mental illness, severe dementia or significant intellectual disability' and '(a) because of the illness, disability or dementia, there is a serious likelihood of the person concerned causing immediate and serious harm to himself or herself or to other persons, or (b) (i) because of the severity of the illness, disability or dementia, the judgment of the person concerned is so impaired that failure to admit the person to an approved centre would be likely to lead to a serious deterioration in his or her condition or would prevent the administration of appropriate treatment that could be given only by such admission, and (ii) the reception, detention and treatment of the person concerned in an approved centre would be likely to benefit or alleviate the condition of that person to a material extent'.

A number of initial concerns arise upon consideration of Section 3(1)(a) which permits involuntary admission on the basis of 'serious likelihood of... immediate and serious harm'. Case law has, regrettably, failed to definitively determine what is meant by 'harm' for the purposes of the Act. Does it refer only to physical and 
psychological harm or could it possibly extend to other types of harm, such as reputational harm, and, if so, to what extent? Unfortunately, the requirement of seriousness offers little clarity in this regard and might only serve to complicate the matter further.

It is also noteworthy that there is no mention of treatment in Section 3(1)(a). By providing for involuntary admission based solely on risk without a reciprocal requirement for benefit from treatment, it is legally possible that a person would be involuntarily admitted on the basis of risk without any prospect of therapeutic benefit from either admission or treatment. As pointed out by the Expert Group (p.21), 'the principle of reciprocity demands if someone's liberty is taken away, there is a parallel duty on the health services to provide appropriate treatment for the person's mental illness'. Section 3(1)(a) clearly fails to meet this requirement.

The lack of a definition of 'harm' and the absence of a requirement for therapeutic benefit in Section 3(1)(a) also blur the distinction between mental health law and criminal law. Inpatient psychiatric facilities are not prisons and should not be used as such. Even if preventive detention on the basis of so-called 'risk' were to occur in Ireland, it should not be possible in psychiatric facilities which are primarily designed for the treatment of illness and not for the prevention of violence or crime.

In a 2020 case before the High Court involving an 18year-old woman with a personality disorder, who was on bail from the District Court in relation to charges of alleged assault and recently said she might kill her mother or other women, Irvine J. ordered the disclosure of material concerning the 'imminent' risk posed by the woman to Gardaí on the grounds that there was no basis for her continued detention or wardship proceedings (Carolan, 2020). While concern was expressed about the threat this woman allegedly posed to the community, the right to autonomy includes the right to make one's own choices, however ill-informed they may appear. In the absence of mental disorder as defined in the 2001 Act (which excludes personality disorder), it is criminal law, rather than mental health law, that should provide for situations where a person's decisions possibly place others in jeopardy.

The situation is, however, rendered more complex by the wording of Section 8(2) which states that 'nothing in subsection (1) shall be construed as authorising the involuntary admission of a person to an approved centre by reason only of the fact that the person (a) is suffering from a personality disorder, (b) is socially deviant, or (c) is addicted to drugs or intoxicants'. Use of the word 'or' rather than 'and/or' in this section means it is not clear if someone who has two or three of the listed conditions can be subject to involuntary admission on that basis. This issue is rendered more acute by the vague mention of 'serious likelihood' of 'immediate and serious harm' in Section 3(1)(a) and the fact that, in 2010, persons with a personality disorder or substance use disorder made up 5\% of involuntary admissions (Ramsay et al. 2013). Clearly, these exclusions require clarification.

In addition, even if these exclusions are clarified, it is not clear if personality disorder should be excluded as a criterion for involuntary admission. In England and Wales, the Mental Health Act, 1983 (as revised) states simply that 'mental disorder' means 'any disorder or disability of the mind' (Section 1(2)). One of the arguments for viewing personality disorder as separate to 'mental disorder' (as is the case in Ireland) appears to be the chronic and enduring nature of some personality disorders, to the extent that, historically, they have sometimes been considered untreatable. Although there has been some shift in this perception in recent years, it remains widely accepted that such treatment, where possible, usually takes place over long periods of time and is best suited to the outpatient setting. Thus, the involuntary admission of a person with a personality disorder, in the absence of another mental illness, would likely not provide therapeutic benefit sufficient to justify the deprivation of liberty involved.

In 2015, the Expert Group (p.22) recommended that Section 3 of the 2001 Act be revised and new criteria for involuntary admission outlined (Kelly, 2015). The Expert Group suggested retaining the exclusion for personality disorder and re-wording Section 8(2) so that 'the involuntary admission of a person to an approved centre cannot be authorised by reason only of the fact that the person (a) is suffering from a personality disorder, (b) is socially deviant, (c) is addicted to drugs or intoxicants, or (d) has an intellectual disability' (p. 23).

\section{Section 57: Mental capacity and treatment without consent}

Section 57(1) of the Mental Health Act, 2001 states that 'consent of a patient [i.e. involuntary patient] shall be required for treatment except where, in the opinion of the consultant psychiatrist responsible for the care and treatment of the patient, the treatment is necessary to safeguard the life of the patient, to restore his or her health, to alleviate his or her condition, or to relieve his or her suffering, and by reason of his or her mental disorder the patient concerned is incapable of giving such consent'.

The first, and arguably greatest, concern about this section is that it separates treatment without consent from involuntary admission by creating a 'capacity test' for treatment without consent while there is no 'capacity test' for involuntary admission (Section 3(1)). This makes it possible, although unlikely, that a patient would fulfil criteria for involuntary admission but still have the mental capacity to decline treatment. Technically, such a patient 
could be admitted as an involuntary patient but could not receive any treatment unless they chose to do so.

If such a patient was involuntarily admitted under Section 3(1)(b), the inability to give treatment would likely mean that the patient would not fulfil the requirement that 'the reception, detention and treatment of the person concerned in an approved centre would be likely to benefit or alleviate the condition of that person to a material extent'. As a result, such an involuntary order would have to be revoked by the treating psychiatrist.

If, however, the patient was admitted under Section 3(1)(a) (i.e. 'a serious likelihood of the person concerned causing immediate and serious harm to himself or herself or to other persons'), there is no legal requirement for the patient to benefit from treatment, so, in theory, such a patient could remain as an involuntary patient indefinitely without any treatment or benefit. Such a situation would likely be a violation of medical ethics but is, nonetheless, legally permitted under the 2001 Act as it stands.

The other notable feature of Section 57(1) is that, while broadly necessitating an involuntary patient's consent for treatment, it accords the treating psychiatrist the responsibilities of assessing the patient's mental capacity to make treatment decisions (if the presumption of capacity is questioned) and deciding if 'the treatment is necessary to safeguard the life of the patient, to restore his or her health, to alleviate his or her condition, or to relieve his or her suffering'. Given that electroconvulsive therapy and psychosurgery are provided for separately (Sections 59 and 58), to what extent must health be restored or suffering relieved by, for example, medication in order to justify treatment without consent?

Section 57(1) appears to try to limit this discretion by specifying that the patient's lack of mental capacity must be attributable to 'his or her mental disorder'. Even so, as is the case with the key term 'best interests' in Section 4(1), the key term 'capable' is not sufficiently defined in Section 56, which states:

In this Part 'consent', in relation to a patient, means consent obtained freely without threats or inducements, where (a) the consultant psychiatrist responsible for the care and treatment of the patient is satisfied that the patient is capable of understanding the nature, purpose and likely effects of the proposed treatment; and (b) the consultant psychiatrist has given the patient adequate information, in a form and language that the patient can understand, on the nature, purpose and likely effects of the proposed treatment.

This provision is both inadequate and inconsistent with the incoming Assisted Decision-Making (Capacity)
Act, 2015 which states that 'a person's capacity shall be assessed on the basis of his or her ability to understand, at the time that a decision is to be made, the nature and consequences of the decision to be made by him or her in the context of the available choices at that time' (Section 3(1)). Unlike the 2001 Act, the 2015 Act provides considerable further detail about the components of mental capacity (Section 3(2)).

The 2015 Act, which has yet to be fully commenced, supports the objective of the CRPD 'to promote, protect and ensure the full and equal enjoyment of all human rights and fundamental freedoms by all persons with disabilities, and to promote respect for their inherent dignity' (Article 1). To this end, and in contrast to the Mental Health Act, 2001, the 2015 Act provides a detailed definition of mental capacity and a more structured framework within which mental capacity is to be assessed (Kelly, 2017). A similarly robust approach is needed in order to safeguard the rights of involuntary patients under the 2001 Act. In addition, any revisions of the 2001 Act should be compatible with the 2015 Act. Various issues relating to the current use of wardship and inherent jurisdiction of the High Court also require careful consideration (Gulati et al. 2020). Some of these matters might be addressed when the 2001 Act is revised.

In 2015, the Expert Group made a number of recommendations in relation to mental capacity, including that the Mental Health Commission should develop and publish guidelines in relation to the assessment of capacity' (p.27). In addition, the Expert Group made several suggestions in relation to 'consent to treatment' and Sections 56 and 57, including that:

- The right of voluntary patients to refuse treatment should be explicitly stated (p.59).

- All patients should be supported to make informed decisions regarding their treatment and 'consent' as defined in Section 56 relating to the consent to treatment should include consent given by a patient with the support of a family member, friend or an appointed 'carer', 'advocate' or a support decisionmaker appointed under the proposed capacity legislation (p.59).

- Section 57 should be amended so that the informed consent of a voluntary patient is required for all treatment (p.59).

- Informed consent is also required for involuntary patients who are deemed capable of giving such consent (p.60).

- A consultant psychiatrist, after consultation (to be officially recorded) with at least one other mental health professional of a different discipline involved in the treatment of the patient, may administer treatment to a detained patient who lacks capacity where the patient does not have a 
DMR [Decision-Making Representative appointed under capacity legislation] and the consultant psychiatrist considers it immediately necessary for the protection of life of the person, for protection from a serious and imminent threat to the health of the person, or for the protection of other persons that he or she should receive such treatment and there is no safe and effective alternative available (p.60).

- A consultant psychiatrist can override the decision of a DMR to refuse treatment on behalf of an involuntary patient in emergency circumstances where the treatment is deemed necessary, the patient is injurious to self or others and no other safe option is available. A Mental Health Review Board [the proposed new title for Mental Health Tribunals] must meet within 3 days to determine that the treatment was given in the appropriate emergency circumstances (p.60).

\section{Recommendations}

Ireland's Mental Health Act, 2001 requires revision. Such revision would be best accomplished through a single, comprehensive piece of amending legislation that revises the Act as a whole and ensures both internal consistency and external consistency with other legislative developments. It would be unwise to commence small pieces of amending legislation in isolation. Such amendments might ostensibly improve specific, isolated areas of the 2001 Act, but would create significant difficulties with other parts of the legislation. In this paper, we focus our suggestions on Sections 4, 3, and 57 of the 2001 Act, but wish to emphasise that any revision of these sections should be embedded within a more comprehensive package of reforms of the Act as a whole that is consistent with other relevant developments, such as the Assisted Decision-Making (Capacity) Act, 2015.

With regard to Section 4 ('Best interests, etc., of person'), the Expert Group recommended that 'insofar as practicable, a rights-based approach should be adopted', with particular emphasis on 'the highest attainable standard of mental health', 'the person's own understanding of his or her mental health being given due respect', 'autonomy', 'self-determination', 'dignity', 'bodily integrity', and 'least restric-

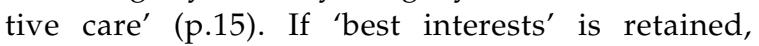
interpretative guidelines similar to those in the Mental Capacity Act (Northern Ireland), 2016 would be useful, taking clear account of the patient's will and preferences.

With regard to Section 3 ('Mental disorder' and criteria for involuntary admission), the Expert Group recommended revised criteria which include a requirement for all involuntary patients that the reception, detention and treatment of the person concerned in an approved centre would be likely to benefit the condition of that person to a material extent' (p.22). This stipulation is vital if Ireland's mental health legislation is to achieve a reasonable balance between rights to liberty and treatment, and fulfil the obligation on mental health services to benefit those they deprive of their liberty. It is also important that any revised legislation does not risk confusion between mental health and criminal law. On this basis, if involuntary admission based on risk is to be continued, 'risk' and 'harm' should be defined as clearly as possible and appropriate provision made for treatment.

With regard to Section 57 ('Treatment not requiring consent'), it is important that any definition and assessment of mental capacity under revised mental health legislation are consistent with the 2015 Act. The definition of mental capacity should be clear and robust, and assessment of mental capacity should accord with appropriate guidelines, as recommended by the Expert Group (p.27). It should not be possible, even in theory, for a patient to be involuntarily admitted and not receive any treatment. If preventive detention on the basis of risk alone, rather than treatable mental disorder, is to occur at all, it should not occur in psychiatric facilities.

While it might be argued that embracing a human rights-based approach to the extent suggested here is somewhat aspirational, it is important to balance achievable goals with higher ideals if progress is to be made and rights are to be respected, including the right to treatment as well as rights to liberty, dignity and autonomy. These rights do not stand in opposition to each other. For many people with severe mental illness, realising the right to treatment is an essential step towards realising the right to liberty.

\section{Acknowledgements}

The authors are very grateful to the editor and reviewers for their comments and suggestions.

\section{Conflict of interest}

Katherine Reidy states that she has no conflict of interest. Brendan D. Kelly was a member of the Expert Group on the Review of the Mental Health Act, 2001 but has no other conflict of interest.

\section{Ethical standards}

The authors assert that all procedures contributing to this work comply with the ethical standards of the relevant national and institutional committee on human 
experimentation with the Helsinki Declaration of 1975, as revised in 2008. The authors assert that ethical approval for publication of this perspective article was not required by their local Ethics Committee.

\section{Financial support}

This research received no specific grant from any funding agency, commercial, or not-for-profit sectors.

\section{References}

Beyleveld D, Brownsword R (2001). Human Dignity in Bioethics and Biolaw. Oxford University Press: Oxford.

Carolan M (2020). Judge orders Gardaí be given material on 'traumatised, dangerous' woman. Irish Times, 18 September. (https:/ / www.irishtimes.com/news/crime-and-law / courts/high-court/judge-orders-garda $\% \mathrm{C} 3 \% \mathrm{AD}$-be-givenmaterial-on-traumatised-dangerous-woman-1.4358401). Accessed 28 September 2020.

Council of Europe (1950). European Convention on Human Rights (Convention for the Protection of Human Rights and Fundamental Freedoms). Council of Europe: Strasbourg. (https://www.echr.coe.int/documents/convention_eng. pdf). Accessed 28 September 2020.

Expert Group on the Review of the Mental Health Act, 2001 (2015). Report of the Expert Group on the Review of the Mental Health Act, 2001. Department of Health: Dublin. (https:/ /www.gov.ie/en/publication/637ccf-report-ofthe-expert-group-review-of-the-mental-health-act-2001/). Accessed 28 September 2020.

Gulati G, Whelan D, Murphy V, Dunne CP, Kelly BD (2020). The inherent jurisdiction of the Irish High Court: interface with psychiatry. International Journal of Law and Psychiatry 69, 101533.
Kelly BD (2005). Structural violence and schizophrenia. Social Science and Medicine 61, 721-730.

Kelly BD (2014). Dignity, human rights and the limits of mental health legislation. Irish Journal of Psychological Medicine 31, 75-81.

Kelly BD (2015). Revising, reforming, reframing: Report of the Expert Group on the Review of the Mental Health Act, 2001 (2015). Irish Journal of Psychological Medicine 32, 161-166.

Kelly BD (2017). The Assisted Decision-Making (Capacity) Act 2015: what it is and why it matters. Irish Journal of Medical Science 186, 351-356.

Koffeman NR (2010). (The Right to) Personal Autonomy in the Case Law of the European Court of Human Rights. Leiden University: Leiden. (https://openaccess. leidenuniv.nl/bitstream/handle/1887/15890/N.R. + Koffeman $+-+($ The + right $)+$ to + personal+autonomy + in + the + case + law + of + the + ECtHR $+(2010)$.pdf;jsessionid $=$ EE037547A594FEE204FC359ADE188458? sequence=3). Accessed 28 September 2020.

Law Committee of the College of Psychiatrists of Ireland (2016). Commentary on Report of Expert Group Review of the Mental Health Act, 2001. College of Psychiatrists of Ireland: Dublin. (https:/ / www.irishpsychiatry.ie/wp-content/ uploads/2017/04/CPsychI-Commentary-on-Report-ofExpert-Group-Review-of-the-Mental-Health-Act-2001-.pdf). Accessed 28 September 2020.

Ramsay H, Roche E, O'Donoghue B (2013). Five years after implementation: a review of the Irish Mental Health Act, 2001. International Journal of Law and Psychiatry 36, 83-91.

United Nations (2006). Convention on the Rights of Persons with Disabilities. United Nations: Geneva. (https:/ /www. un.org/development/desa/disabilities/convention-onthe-rights-of-persons-with-disabilities / convention-on-therights-of-persons-with-disabilities-2.html). Accessed 28 September 2020. 